\title{
Prioritization of Factors Affecting Time Management among Health Managers
}

\author{
Mohammadkarim Bahadori ${ }^{1}$, Mahmood Salesi ${ }^{1}$, Ramin Ravangard ${ }^{2}$, Seyed Mojtaba Hosseini ${ }^{3}$, Mehdi Raadabadi ${ }^{4}$, Amin \\ Hojati Dana1, Ahmad Ameryoun, ${ }^{1, *}$ \\ ${ }^{1}$ Health Management Research Center, Baqiyatallah University of Medical Sciences, Tehran, Iran \\ ${ }^{2}$ Department of Health Services Management, School of Management and Medical Information Sciences, Shiraz University of Medical \\ Sciences, Shiraz, Iran \\ ${ }^{3}$ Department of Health Services Management, Tehran North Branch, Islamic Azad University, Tehran, Iran \\ ${ }^{4}$ Research Center for Health Services Management, Institute for Futures Studies in Health, Kerman University of Medical Sciences, Kerman, \\ Iran
}

*Corresponding Author: Ahmad Ameryoun, Associate Professor. Ph.D. in Health Services Management, Health Management Research Center, Baqiyatallah University of Medical Sciences, Mollasadra Street, Tehran, Iran. Email: ad_amer_heli@yahoo.com

\begin{abstract}
Introduction: In today's world, having principle and targeted management is one of the progress and development factors of any organization. Effective use of time for each manager is the most important base for managing current affairs and controlling daily activities. The present study aimed to investigate and analyze the relationship between factors affecting time management among the senior, middle and first-line managers of the hospitals in Kermanshah in 2015.

Methods: This was a cross-sectional and descriptive-analytical study conducted in 2015 in ten hospitals of Kermanshah. The study population consisted of all senior, middle and first-line managers of the studied hospitals $(\mathrm{N}=240)$ which were selected using census method. The required data were collected using a researcher-made pair-wise comparison questionnaire. The collected data were analyzed using the DEMATEL technique through Matlab8.1.0.604 software.

Results: The results showed that, from the studied managers' viewpoints, the variables of goal setting and prioritization of objectives and activities were certainly affecting variables and located in the cause group. Also, the variables of planning, delegation, communication management, and meetings management were affected variables and located in the effect group. Furthermore, in the hierarchy of affecting and affected variables influencing time management, goal setting and meetings management with the coordinates $(1.23,1.23)$ and $(1.06,-1.05)$ were identified as the highest and lowest priorities and were considered as the most affecting and most affected variables, respectively.

Conclusion: The results of the present study showed that among the studied variables influencing time management, goal setting was the highest priority and most affecting variable, and meetings management was the lowest priority and the most affected variable. It is recommended to increase the hospital managers' knowledge about time management and the need for accurate goal setting through providing management and time management courses, and requiring them to develop a time management plan in order to improve their time management.
\end{abstract}

Keywords: Time Management, Health Managers, DEMATEL

Article History: Received: 15 Apr. 2015; Accepted: 17 Jul. 2015; Online Published: 26 Nov. 2015

Cite this article as: Bahadori M, Salesi M, Ravangard R, Hosseini SM, Raadabadi M, Hojati Dana A, et al. Prioritization of factors affecting time management among health managers. Int J Travel Med Glob Health. 2015;3(4):159-64.

\section{Introduction}

In Management literature, the proper use of resources to meet the organizational goals and objectives is considered as one of the most important managers' duties. Resources available to managers and organizations include human resources, financial resources, information resources, etc. Time is also one of these resources that, like some other resources such as experience, talent and intelligence, is intangible to which less attention has been paid [1]. Therefore, accurate and timely understanding of the factors wasting time in order to eliminate or control them is very important. In the meantime, managers should be aware of their work rhythm and activities and should learn how to organize them based on all factors influencing the performance [2]. Because most of managers' time is spent attending meetings and making important decisions related to the issues of lower levels of the organization, the use of time management can prevent waste of time. In fact, improving the senior managers' ability to manage time properly and increase the employees' motivation for using their maximum capabilities is a factor that will ensure the success of organizations in the global competitiveness[3].

Time management means the effective use of time through performing specified targeted activities [4] and includes behaviors that aim to make effective use of time during the implementation of certain targeted activities[5]. This skill is a broad concept in different areas of administration and management which is associated with the improvement of performance quality and its application can eliminate or reduce many daily pressures on the managers [6]. The concept of time management has been paid more attention from the 1950s [7]. Time management can be considered as a way to monitor and control time [8]. By using time management techniques, the individuals' insight about how to use their time will increase [9], the time required to get things done can be estimated more precisely, and the better results and outcomes can be achieved by more realistic planning [10].

Researchers have defined "time management" as prioritizing and planning tasks and activities, the ability to say no, limiting interruptions, making good investment in time, and controlling time carefully by the individual [11]. Time management has very important individual and organizational effects. The results of studies have shown that the use of time management skills can result in improved job performance [12], devoting more time to tasks with a higher priority [13], accelerating the progress of work [14], and increasing individuals' job satisfaction [15]. Oji and 
Olaniyan in their study entitled "Effective Time Management in Organization Panacea or Placebo" have stated that the aim of time management is to allocate more time to think about the tasks and duties, not performing more tasks in less time [16]. Also, Arnold and Pulich believe that time management is the best use of precious and valuable time to achieve the personal and occupational goals and establishes a direct association between performing the daily tasks and ensuring job satisfaction and progress [17]. Cleassens considers time as a pressure factor everywhere and states that time management is an effective tool to deal with this problem [3].

Therefore, given the importance of studying time management and the managers' crucial role in organizational success and that time management is one of the most important indicators of effectiveness and success, it is important to consider factors affecting it. Claessens and colleagues in their study have concluded that factors such as the prioritization of tasks and activities, delegation, proper management of meetings, and planning for occupational and personal affairs are effective factors influencing time management [4]. Hasoomi and Sarikhani in their study have found that three principles of time management include setting the goal, determining the priorities and adhering the priorities [18]. Araghieh and colleagues also have described time management as the prioritization of objectives and the use of available resources to achieve short-term and longterm goals [19].

On the other hand, the need for leadership and management in all fields of social activity is an important and vital issue. Without an effective leadership, human and non-human resources move quickly towards decline and destruction. In the meantime, time management is of particular importance in the profession of health managers. As wasted time is a time that has not been spent providing services for patients and if time management is forgotten when working, its negative effects will be for patients [20]. In addition, the dynamics of health care systems and the need for constant interaction with the external environment increases the importance of acquiring time management skills for health managers [21]. However, despite the fact that the use of these skills is an important component of professional practice of health managers, such skills have not been considered carefully [22] and there is not any attempt to extend the available time in order to prevent stresses caused by time pressures and meet the patients' needs through learning time management techniques [4].

Time management in the health sector, especially in hospitals at all levels of managers, including senior, middle and first-line, which has direct relationship with the public health, is very important. Waste of time in different areas of hospital management, including planning, decision making, organization, implementation and control can cause irreversible side effects and decrease productivity[23].

The present study aimed to investigate and analyze the relationship between factors affecting time management among the senior, middle and first-line managers of the hospitals in Kermanshah in 2015.

\section{Methods}

This study was a cross-sectional and descriptive-analytical study conducted in 2015 in ten hospitals of Kermanshah, including one military hospital, seven public hospitals affiliated to the Ministry of Health and Medical Education, and two hospitals affiliated to the Social Security Organization. The characteristics of the studied hospitals have been presented in Table 1 .

Table 1. The characteristics of the studied hospitals

\begin{tabular}{|c|c|c|c|c|}
\hline $\begin{array}{l}\text { Hospital } \\
\text { Name }\end{array}$ & Ownership and Affiliation & Scope & $\begin{array}{l}\text { Number of } \\
\text { Beds }\end{array}$ & $\begin{array}{c}\text { Accreditation } \\
\text { Degrees }\end{array}$ \\
\hline A & $\begin{array}{l}\text { Ministry of Health and Medical Education } \\
\text { (University of Medical Sciences) }\end{array}$ & A Teaching, and Specialty and Subspecialty Hospital & 550 & 1 \\
\hline $\mathrm{C}$ & (University of Medical Sciences) & A Teaching, and Specialty and Subspecialty Hospital & 150 & 1 \\
\hline $\mathrm{D}$ & Ministry of Health and Medical Education & A Teaching, and Specialty and Subspecialty Hospital & 150 & 2 \\
\hline $\mathrm{E}$ & (University of Medical Sciences) & A Teaching, and Women (Specialty and Subspecialty) Hospital & 150 & 2 \\
\hline $\mathrm{F}$ & Ministry of Health and Medical Education & A Teaching, and Heart (Specialty and Subspecialty) Hospital & 250 & 1 \\
\hline $\mathrm{H}$ & Social Security Organization & A Specialty and Subspecialty Hospital & 150 & 2 \\
\hline I & Social Security Organization & A Women (Specialty and Subspecialty) Hospital & 150 & 1 \\
\hline $\mathrm{J}$ & The Iranian Revolutionary Guards (Military Hospital) & A General and Specialty Hospital & 150 & 1 Excellent \\
\hline
\end{tabular}

The study population consisted of all senior, middle and first-line managers of the studied hospitals $(\mathrm{N}=240)$, including 30 senior managers, 50 middle managers and 160 first-line managers. All managers were selected using the census method. senior managers included the hospital heads and administrators and matrons,; the middle managers included clinical supervisors (morning, afternoon and evening supervisors), training supervisors, and accreditation and clinical governance supervisors; and finally, the firstline managers were the head nurses of wards, including the internal medicine, surgery, gynecology, pediatric, ICU, CCU, NICU, POST CCU, and POST ICU, as well as the heads of paraclinical wards, including laboratory, radiology, MRI, physiotherapy, speech therapy, occupational therapy, the clinic, etc.

The required data were collected using a researcher-made pair-wise comparison questionnaire designed based on the previous studies on time management [24-25] and consultation with the related experts in the field of time management. The questionnaire consisted of six variables, including goal setting, prioritization of objectives and activities, planning, delegation, communication management, and meetings management, in which they were compared with each other two by two. To determine the relationships between the studied variables, the responses of very high impact, high impact, low impact, and without any impact rated as 3,2,1 and 0, respectively. The validity of the questionnaire was confirmed using the experts' opinion, and its content validity also was approved (CVI $=0.75$, $\mathrm{CVR}=0.8)$. Moreover, its reliability was approved using Cronbach's alpha $(\alpha=0.70)$. Before conducting the study, necessary permissions for carrying out the study were 
received from the senior managers of the studied hospitals. During the study and for collecting required data, the appointments with the managers were made and their consent to participate in the study was obtained and adequate explanations on how to respond to the questions were given to them. The collected data were analyzed using the DEMATEL technique, which is one of the group decisionmaking techniques for structuring factors influencing an event and classifying them into factors affecting or affected by the event, through Matlab 8.1.0.604 software.

\section{Results}

The results showed that most of the studied hospital managers were male (71.2\%), married $(91.2 \%)$, in the $30-40$ age group (52.2\%), working as the head of nurses and the heads of paraclinical wards $(66.7 \%)$, and had between 11 and 20 years job experience $(67.1 \%)$ and bachelor's degrees (57.1\%) (Table 2).

Table 2 shows the effects of studied variables on each other from the managers' viewpoints through pair-wise comparisons. Figure 1 shows that, according to the hierarchy graph of time management variables, goal setting and meetings management with the coordinates $(1.23,1.23)$ and $(1.06,-1.05)$ were identified as the highest and lowest priorities of variables influencing time management and were considered as the most affecting and most affected variables, respectively.

The results showed that, from the studied managers' viewpoints, the variables of goal setting and prioritization of planning, delegation, communication management, and meetings management were affected variables and located in the effect group (Table 3).

\section{Discussion}

The results about goal setting showed that this variable, from the perspective of the studied managers, was certainly an affecting variable influencing time management and was located in the cause group. In the hierarchy graph of objectives and activities were certainly affecting variables and located in the cause group. Furthermore, the variables of

variables influencing time management, this variable with the coordinate of $(1.23,1.23)$ was the first priority.

Table 2. Demographic characteristics of the studied managers $(n=240)$

\begin{tabular}{|c|c|c|}
\hline & Variables & Frequency $(\%)$ \\
\hline \multirow{2}{*}{ Sex } & Male & $171(71.2)$ \\
\hline & Female & $69(28.8)$ \\
\hline \multirow{3}{*}{ Age (years) } & $<30$ & $28(11.6)$ \\
\hline & $30-40$ & $125(52.2)$ \\
\hline & $>40$ & $87(36.2)$ \\
\hline \multirow{2}{*}{ Marital Status } & Married & $219(91.2)$ \\
\hline & Single & $21(8.8)$ \\
\hline \multirow{3}{*}{$\begin{array}{l}\text { Job Experience } \\
\text { (years) }\end{array}$} & $1-10$ & $41(17.1)$ \\
\hline & $11-20$ & $161(67.1)$ \\
\hline & $21-30$ & $38(15.8)$ \\
\hline \multirow{7}{*}{ Position } & Head of Hospital & $10(4.2)$ \\
\hline & Hospital Manager & $10(4.2)$ \\
\hline & Matron & $10(4.2)$ \\
\hline & Clinical Supervisor & $30(12.5)$ \\
\hline & Training Supervisor & $10(4.2)$ \\
\hline & $\begin{array}{l}\text { Accreditation and Clinical } \\
\text { Governance Supervisor }\end{array}$ & $10(4.2)$ \\
\hline & $\begin{array}{l}\text { Head Nurses and the Heads } \\
\text { of Paraclinical Wards }\end{array}$ & $160(66.7)$ \\
\hline \multirow{4}{*}{$\begin{array}{l}\text { Education } \\
\text { Level }\end{array}$} & Bachelor's Degrees & $137(57.1)$ \\
\hline & Master's Degrees & $90(37.5)$ \\
\hline & $\begin{array}{c}\text { Professional Doctorate } \\
\text { Degrees }\end{array}$ & $7(2.9)$ \\
\hline & Ph.D. Degrees & $6(2.5)$ \\
\hline
\end{tabular}

Table 3. The affecting and affected variables influencing time management

\begin{tabular}{lcccc}
\hline Variables & $\mathbf{R}^{*}$ & $\mathbf{J}^{*}$ & $\mathbf{R}+\mathbf{J}^{*}$ & $\mathbf{R}-\mathbf{J}^{*}$ \\
\hline $\begin{array}{l}\text { Goal setting } \\
\text { Prioritization of } \\
\text { objectives and activities }\end{array}$ & 1.23 & 0 & 1.23 & 1.23 \\
$\begin{array}{l}\text { Planning } \\
\text { Delegation }\end{array}$ & 0.46 & 0.2 & 1.07 & 0.6698 \\
$\begin{array}{l}\text { Communication } \\
\text { management }\end{array}$ & 0.31 & 0.40 & 0.72 & -0.094 \\
$\begin{array}{l}\text { Meetings management } \\
\text { R: The highest row sum, J: The highest column sum, R+J: The total sum } \\
\quad\end{array}$ & 0.12 & 0.83 & 0.96 & -0.7126 \\
&
\end{tabular}

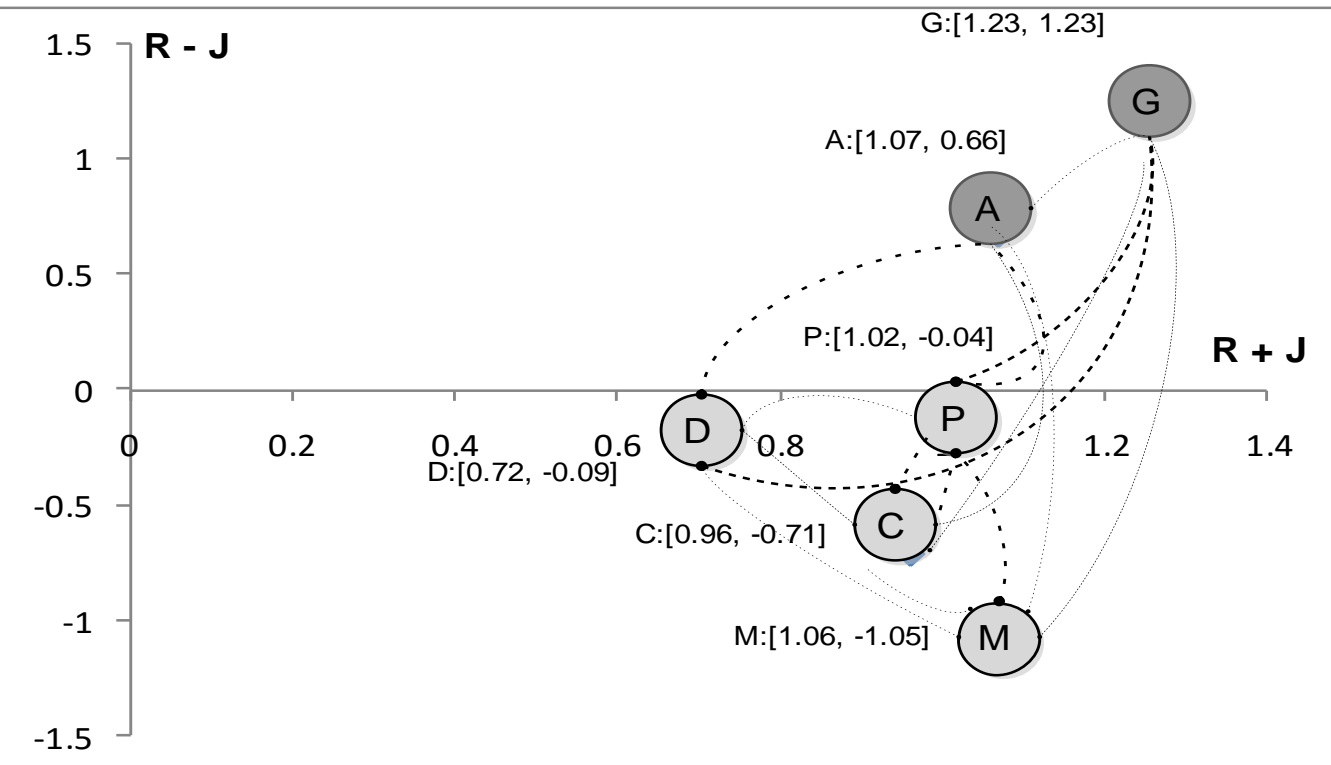

G: Goal setting, A: Prioritization of objectives and activities, P: Planning, D: Delegation, C: Communication management, M: Meetings management

Figure 1. The hierarchy of affecting and affected variables influencing time management from the studied hospital managers' viewpoints 
Unlike the results of the present study, this variable had received the second priority in the Kebriaei and colleagues' study[26]. Furthermore, the results of Sternberg's study showed that planning and goal setting had the first and last priorities, respectively [27].

Considering that goal setting in the present study was an affecting variable influencing time management and is the first step in time management, if the goals and objectives are set wrongly, this creates problems in the other steps and makes it difficult for managers to achieve successful time management. Therefore, time allocation on the basis of objectives enables managers to identify their work processes. Time management and the effective use of time in today's world is essential for development and promotion, and causes people to engage in activities which meet their individual goals[28].

The results about the prioritization of objectives and activities showed that, from the studied managers' viewpoint, this variable was certainly an affecting variable influencing time management and located in the cause group, which is similar to the results of Hafeziand colleagues [29], Ziegler [30] and Steinert and colleagues' [31] studies and is different from the results of Alamand colleagues' study [31] . People can complete multiple tasksin a timely manner and achieve self-discipline state through applying time management, accurately estimating the time required to get things done, and prioritizing activities [32]. In time management, determining work priorities and the more urgent activities is very important to the extent that experts consider it as the essence of time management and believe that $80 \%$ of time can be allocated for performing only $20 \%$ of the high priority tasks and activities [32]. The prioritization of objectives and activities is of particular importance because managers, in addition to their personal goals, are faced with organizational goals. It is said that for in order to meet those goals as well, a certain amount of time should be spent.

The planning variable which had been located in the affected variables group, finally got located in in the hierarchy of affecting and affected variables influencing time management. The results of the present study are in line with those of Marriner [33], Fitsimmons [34], Zampetakis and colleagues [1], and Ghaedmohammadi's [35] studies, in which there were significant and positive associations between the personal skills of time management and operational planning skills, and are inconsistent with the results of Hashemizadeh's study [36]. Overall, the results of various studies indicate that poor and inappropriate time planning can result in the lack of success in the activities, allocation of insufficient time to other personal and social activities, and increased stresses[39-41]. Moreover, Zampetakisand colleagues believe that time management is basically a process of planning which includes decisions about the activities that should be done, prioritizing them, and effective management of the troublesome factors. Therefore, it can be said that among the other dimensions of organizational skills, time management is the most important one. Moreover, perhaps the personal skill of time management can be emphasized as a useful tool for effective management[1].

In the hierarchy of affecting and affected variables influencing time management, delegation is located in the affected variables group. The results of Alam and colleagues [31] and Mohammadian and colleagues' [37] studies showed that delegation was in the middle priorities, which are in line with the results of the present study. Hospital managers can become a good and appropriate model for their employees through applying effective time management. They can also lead to their employees' innovation and growth by delegating authorities and tasks to and setting deadlines for them. Therefore, breaking large tasks into smaller ones and scheduling them cause employees to complete the work and feel satisfaction [38]. New strom and Davis consider incorrect delegation as one of the reasons for managers' failure [39]. Drucker believes that effective managers should organize tasks and activities so that they themselves address only the major issues in order to achieve excellent results. A good manager should first do his/her activities that are more important and high priorities and it is better to delegate the less important ones and those are low priorities to others. Delegation becomes more important with the development of organizations to the extent that the survival of the organization will be impossible without delegating the authorities and tasks[40].

Communication management, in the hierarchy of affecting and affected variables influencing time management, located in the affected variables group, was similar to the results of Lewis's study [41]. Also, the results of Alam and colleagues' study [31] showed that communication management had a significant impact on time management, and time management had been influenced by communication management, which are consistent with the results of the present study. Organizational communication is a process which enables managers to obtain information and exchange information with many people inside and outside the organization. If managers recognize that such relationships are in line with meeting their organizational objectives, they should use them and when they recognize that they are different from and opposite to their organizational goals and objectives, they should try to stop such relationships so that they can decrease the related tension and stresses. Considering that many managers' individual and organizational problems are rooted in their poor communication skills, providing the opportunities for promoting their individual skills in time management and creating the required environment in the organization in which people can use their individual skills in order to communicate more effectively are very essential.

In the hierarchy of affecting and affected variables influencing time management, meetings management with the coordinates $(1.06,-1.05)$ was the lowest priority. The results of Alam and colleagues [31] and Mohammadian and colleagues' [37] studies are similar to the results of the current study. Furthermore, this variable was the most affected variable. Fiedler believes that meetings take a lot of managers' time and meetings management is considered as an art [42]. Ferner and colleagues in their study have also concluded that among there are for waste of time, meetings are considered as one of the worst factors[43], which is in line with the results of the present study. Therefore, in organizations which meetings take a lot of managers' time, meetings management and the prevention of holding unnecessary meetings can save a lot of time for managers.

The present study had a limitation. In the present study, a pair-wise comparison questionnaire was used to investigate and analyze the relationship between factors affecting time management among the studied senior, middle and first-line hospital managers and such questionnaires require enough 
time and great attention and concentration when completed. These requirements could not be met by some of the managers participating in this study which could result in not obtaining accurate data.

\section{Conclusion}

In conclusion, the results of the present study showed that among the studied variables influencing time management, goal setting was the highest priority and affecting variable and meetings management was the lowest priority and the most affected one. As goal setting is the first step in effective time management and represents the quality and method of spending time by employees in the future, more investment in this variable and setting precise and measurable objectives by the managers can save time in later stages. In order to achieve correct and proper time management, it is recommended setting and prioritizing clear goals and objectives, as well as determining and clarifying tasks accurately. In this regard, increasing hospital managers' knowledge about time management and the need for accurate goal setting through providing management and time management courses, and requiring them to develop a time management plan can improve their time management.

\section{Acknowledgments}

The researchers would like to thank the studied hospitals heads and staff, as well as all the patients participating in this study for their kind cooperation with the researchers in collecting and analyzing the data.

\section{Authors' Contributions}

Mohammadkarim Bahadori and Seyed Mojtaba Hosseini conducted the study concept and design and developed the methods. Amin Hojati Dana collected the data. Mohammadkarim Bahadori and Mahmood Salesi analyzed and interpreted the data. Ramin Ravangard and Mehdi Raadabadi wrote the primary draft of the manuscript. All of the authors contributed to the revision of the manuscript, read, and approved the final version.

\section{Financial Disclosure}

The authors declare no financial interests related to the material in the manuscript.

\section{Funding/Support}

Our study was funded by the Baqiyatallah University of Medical Sciences.

\section{References}

1. Zampetakis LA, Bouranta N, Moustakis VS. On the relationship between individual creativity and time management. Think Skills Creat. 2010;5(1):23-32.

2. Indreica E-S, Cazan A-M, Truta C. Effects of learning styles and time management on academic achievement. Procedia Soc Behav Sci. 2011;30:1096-102.

3. Claessens BJ, Van Eerde W, Rutte CG, Roe RA. Planning behavior and perceived control of time at work. J Organ Behav 2004;25(8):937-50.

4. Claessens BJ, Van Eerde W, Rutte CG, Roe RA. A review of the time management literature. Personnel Rev. 2007;36(2):255-76.

5. Liu OL, Rijmen F, MacCann C, Roberts R. The assessment of time management in middle-school students. Personality Individual Diff. 2009;47(3):9-147.

6. Britton BK, Tesser A. Effects of time-management practices on college grades. J EducPsychol. 1991;83(3):405.

7. Nonis SA, Teng JK, Ford CW. A cross-cultural investigation of time management practices and job outcomes. Intl $\mathrm{J}$ Intercultural
Relations. 2005;29(4):409-28

8. Eilam B, Aharon I. Students' planning in the process of self-regulated learning. Contemp Educ Psychol. 2003;28(3):304-34.

9. Huy QN. Time, temporal capability, andplanned change. Acad Manage Rev. 2001;26(4):601-23.

10. Francis-Smythe JA, Robertson IT. On the relationship between time management and time estimation. Br J Psychol. 1999;90(3):333-47.

11. Greenberg JS. Comprehensive stress management. 2002.

12. Davis $\mathbf{M}$. Time and the nursing home assistant: Relations among time management, perceived control over time, and work-related outcomes. Academy of Management, Toronto, Canada. 2000.

13. Ziapour A, Khatony A, Jafari F, Kianipour N. Evaluation of time management behaviors and its related factors in the senior nurse managers, Kermanshah-Iran. Glob J Health Sci. 2015;7(2):366-73.

14. Ebrahimi H, Hosseinzadeh R, Tefreshi MZ, Hosseinzadeh S. Time management behaviors of head nurses and staff nurses employed in Tehran Social Security Hospitals, Iran in 2011. Iran J Nurs Midwifery Res. 2014;19(2):193-8.

15. Gran-Moravec MB, Hughes CM. Nursing time allocation and other considerations for staffing. Nurs Health Sci. 2005;7(2):126-33.

16. Ojo L, Olaniyan D. Effective Time Management in Organization Panacea or Placebo. Eur J Sci Res. 2008;24(1):127-33.

17. Arnold E, Pulich M. Improving productivity through more effective time management. Health Care Manag. 2004;23(1):65-70.

18. Hasoomi T, Sarikhani N. The Relationship between Time Management and Job Burn-out among the Staffs in Islamic Azad University zone 12. J Modern Thoughts Educ. 2010;6(1):89-107. Persian

19. Araghieh A, Zahrakar K, Akbari M .The Relationship between Time Management and the Effectiveness of the Secondary School Managers in Bustan and Golestan. J Modern Thoughts Educ. 2012;7(2):73-82. Persian

20. Waterworth S. Time management strategies in nursing practice. J Adv Nurs. 2003;43(5):432-40.

21. Huber D. Leadership and nursing care management. Elsevier Health Sciences; 2013

22. Birkinshaw J, Caulkin S. How should managers spend their time? Finding more time for realmanagement. BSR. 2012;23(4):62-5.

23. Braithwaite J, Westbrook MT. Time spent by health managers in two cultures on work pursuits: real time, ideal time and activities' importance.Int J Health Plan Manag. 2011;26(1):56-69.

24. Hashemizadeh $H$. The Relationship between time management behavior and stress at the head of the surgical teaching hospitals affiliated with the Shahid Beheshti University of Medical Sciences. Quarterly J Fundam Ment Health. 2006;29(8):51-6. Persian

25. Zampetakis L, Bouranta N, Moustakis V. On the relationship between individual creativity and time management. Think Skills Creat. 2010;5(1):23-32.

26. Kebriaei A, Sabahi BM, Saeedi A. Relationship between use of time management skills and satisfaction with spending time among students of zahedan university of medical sciences. J MedEdu Dev. 2014;6(12):79-89.

27. Sternberg RJ. A model of educational leadership: Wisdom, intelligence, and creativity, synthesized. Intl J Leadersh in Educ. 2005;8(4):347-64.

28. Nonis SA, Hudson GI. Academic performance of college students: Influence of time spent studying and working. J Educ Business. 2006;81(3): 15 .

29. Hafezi S, Naghibi H, Naderi E, Najafi MS, Mahmoodi H. The correlation between personal skill and organizational behavioral time management among educational administrators. J Behav Sci. 2008;2(2):183-95. Persian

30. Ziegler E. By Leaps \& Bounds: How to Stop WastingTime, Set Your Priorities, and Soar to Success in the Publications Office. Currents. 1993;19(3):38.

31. Alam Z, Mozaffari SAA, Bagheri H, Marefat D. The Relationship between Personal and Organizational Time Management Skills of Managers of P.E in Khuzestan Province. Res Sport Manag Behav. 2013;3(5):73-83. Persian

32. Macan TH. Time-management training: Effects on time behaviors, attitudes, and job performance. J Psycho. 1996;130(3):229-36.

33. Marriner A. Time Managementthrough Planning. J Contin Educ Nurs. 1983;14(1):21-6.

34. Fitsimmons G. Time management part I: goal setting as a planning tool. Bottom Line. 2008;21(2):61-3.

35. Ghaedmohammadi M. The important factors of students' time management among Islamic Azad University. Social Res. 2010;3(6):57-73.

36. Hashemizadeh H. Analysis of relation between time management behaviors and occupational stress of medical surgical ward's head 
nurses of educational hospitals depend on Shaheed-Beheshti medical university of Tehran, Iran. J Fundam Ment Health. 2012;60(5):S159.

37. Mohammadian A, Jahangiri S, Naghizadeh Baghi A, Pourfarzi F. A Study on Time Management Skills in Ardabil University of Medical Sciences (ARUMS) Managers. J Health Adm. 2006;9(24):59-66.

38. Marquis BL, Huston CJ. Leadership roles and management functions in nursing: Theory and application. Lippincott Williams \& Wilkins; 2009.

39. Newstrom JW, Davis K. Human behavior at work. New York.
McGraw-Hill; 1986.

40. Eghtedari A. Organization and management. Tehran: Molavi Publication. 2001:125. Persian

41. Lewis D. 10-minute Time and Stress Management: How to Gain an'extra'Ten Hours a Week. Piatkus; 1995.

42. Fiedler FE, Chemers MM. Leadership and effective management. Scott, Foresman Glenview, IL; 1974.

43. Ferner JD, Deans J. Successful time management. Clin Lab Manag Rev. 1998;13(1):13-21. 